\title{
BUCKLING ANALYSES OF COMPRESSED STIFFENER WITH FINITE ELEMENT METHODS
}

\author{
T. Katrňák* , J. Juračka**
}

\begin{abstract}
This article presents the research of effect of model imperfections on the local buckling of compressed stiffeners in finite element (FE) analyses. Improved FE models with imperfections provide more accurate simulations of thin-walled semi-monocoque structures, where natural curvatures of structures are insufficient. Main outcomes of these analyses are designs of practical types of imperfections with appropriate ratio values and demonstration of trends from graphic comparisons of results.
\end{abstract}

\section{Keywords: buckling, stress analysis, finite element method, stiffener, imperfection}

\section{Introduction}

The proper determination of the total load capacity of semi-monocoque structure is the crucial aim of stress analyses of aircraft structures. If simulations of particular critical failures of significant structural elements do not correspond to real behavior, the determination of global failure is not accurate. The research of effects on problematic local buckling of compressed stiffeners in finite element analyses was initiated to achieve practical settings of designed imperfections for more accurate numeric simulations. Evaluations of various sets of imperfection types confirmed the necessity of defect application in FE models where natural curvature of structures is not sufficient. Author will use these models and knowledge for following determinations of buckling stress of stiffeners under combined compression and bending loads, where accurate diagrams for a safe design are not available.

The comprehensive reviews on stability failures of compressed stiffeners in aerospace structures are presented by (Niu, 1999), from which an analytic approach of determination of critical buckling forces were used. The paper by (Symonov et al., 2013) contributed with a comparison of nonlinear FE analyses and analytic approaches. Analytical solutions of skin buckling and effects of stringer torsional and warping failures and the verification by finite element methods are presented by (Soares et al., 2013). This topic was extended in the research paper (Hoff 1967), (Horák et al., 2016) and (Pravdová et al., 2017). Measurement techniques and test procedures of aircraft structural parts are described in the paper (Jebáček et al., 2017). Data and description of imperfections from listed references were taken into account to designed FE models with the purpose of determination of appropriate imperfection ratios. The part of this research of buckling sensitivity on applied imperfection was published in student's bachelor thesis (Hála, 2017). This article presents the advanced description of complemented research.

\section{Model and simulations}

The finite element model of typical aircraft structural profile with the cross-sectional L shape and equal flanges was created for numeric simulations. A typical discretization in FE model with three elements in the height of profile flange for buckling analyses with imperfection is presented in Figure 2. After testing simulations with 1D, 2D and 3D element types and comparison of sensitivity of models and the time consumption of simulations, the standard shell elements CQUAD4 were utilized. One side of the

\footnotetext{
* Ing. Tomáš Katrňák: Institute of Aerospace Engineering, Faculty of Mechanical Engineering Brno University of Technology, Technická 2896/2; 616 69, Brno; CZ, katrnak@fme.vutbr.cz

** Assoc. Prof. Jaroslav Juračka, Ph.D.: Institute of Aerospace Engineering, Faculty of Mechanical Engineering Brno University of Technology, Technická 2896/2; 616 69, Brno; CZ, juracka@fme.vutbr.cz
} 
specimen model was fully clamped with multipoint connectors RBE2. The second end of the model was loaded with multipoint connectors RBE2 by the specimen shortening with the maximum value $0.5 \mathrm{~mm}$, which was split to 50 steps with the equal difference $2 \%$ of load $(0.01 \mathrm{~mm})$. The structural analysis was computed in the MSC.MD Nastran 2017.1 software, which enables to use nonlinear buckling behavior for large deformations. The scheme of utilized process, software parts and file types is presented in Figure 1. A post-processing procedure transformed result from the MSC.Patran database to a report file, which was processed in Excel software.

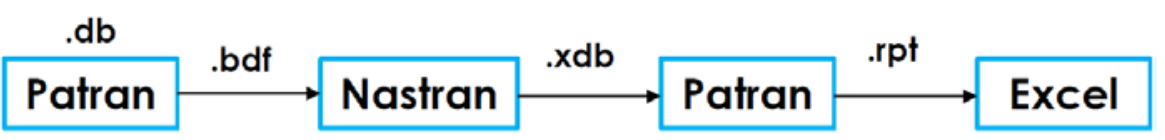

Fig. 1: Scheme of utilized computation and evaluation process.

\section{Comparison of results of model with initial imperfection A}

The initial set of FE models with applied imperfections in the one middle node of the length of the profile flange was marked as the imperfection A and it is displayed in Figure 2.
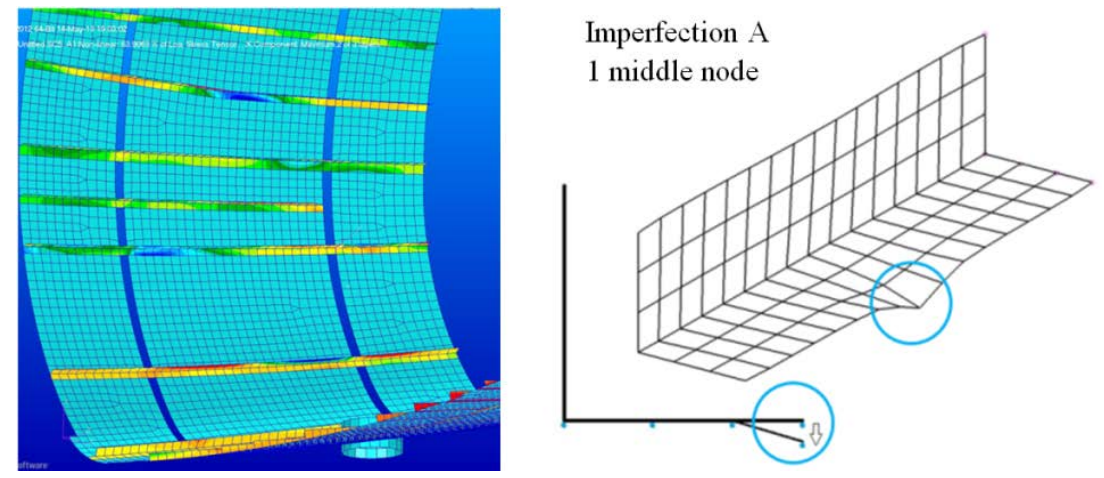

Fig. 2: Stress distribution in stringers of typical semi-monocoque fuselage structure and FE model of the initial set with imperfection A.

The detail comparison of distributions of induced compression force per profile shortening is presented in Figure 3. All force distributions have identical model stiffness up to particular points of buckling instability. Critical buckling forces were compared with the critical force and its tolerance range, which were determined from analytic approach according to (Niu, 1999). Differences of buckling forces and corresponding stresses before the loss of stability are evident also from Table 1, where the numeric results are listed. The trend in effects of imperfection is derived from a drop of buckling forces for increased value of imperfection. The ratio of imperfection per flange thickness e/t equal to 0.2 for this initial set of imperfection A was evaluated as the most suitable dimension of imperfection.

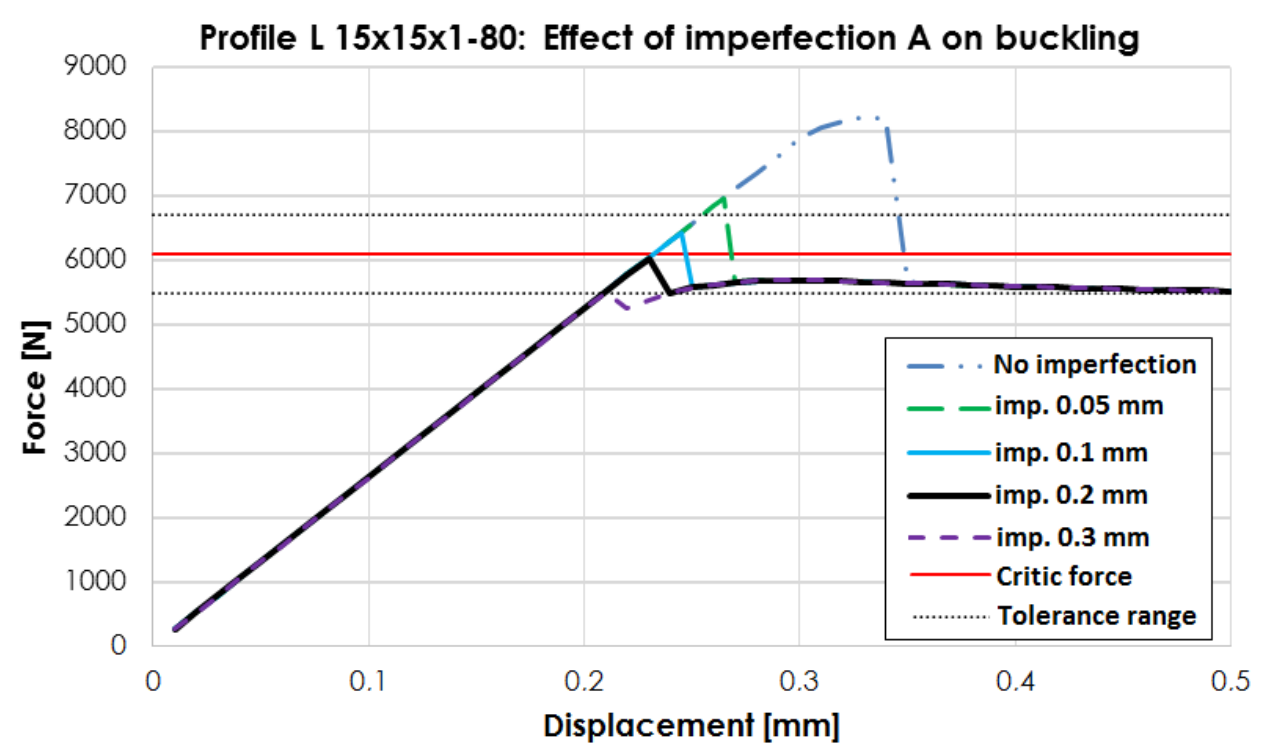

Fig. 3: Graphic comparison of force distributions per model displacement. 
Tab. 1: Numeric comparison of buckling force and buckling stress results.

\begin{tabular}{cccc}
\hline Imperfection & Ratio e/t & Buckling force & Buckling stress \\
\hline$[\mathrm{mm}]$ & {$[-]$} & {$[\mathrm{N}]$} & {$[\mathrm{MPa}]$} \\
\hline 0.00 & 0.00 & 8219 & 280 \\
\hline 0.05 & 0.05 & 6958 & 237 \\
\hline 0.10 & 0.10 & 6431 & 219 \\
\hline $\mathbf{0 . 2 0}$ & $\mathbf{0 . 2 0}$ & $\mathbf{6 0 2 2}$ & $\mathbf{2 0 5}$ \\
\hline 0.30 & 0.30 & 5689 & 194 \\
\hline
\end{tabular}

Also colored graphic visualizations with stress scales were evaluated. The sudden loss of stability in a plastic local mode for a model with the imperfection A equal to ratio e/t $=0.2$ is presented in Figure 4 . The stable level at $46 \%$ of load is depicted on the left part of Figure 4 and the significant change to the buckled mode at $48 \%$ of load on the right figure part. These graphic visualizations allow detail investigation of stress distributions in FE models.
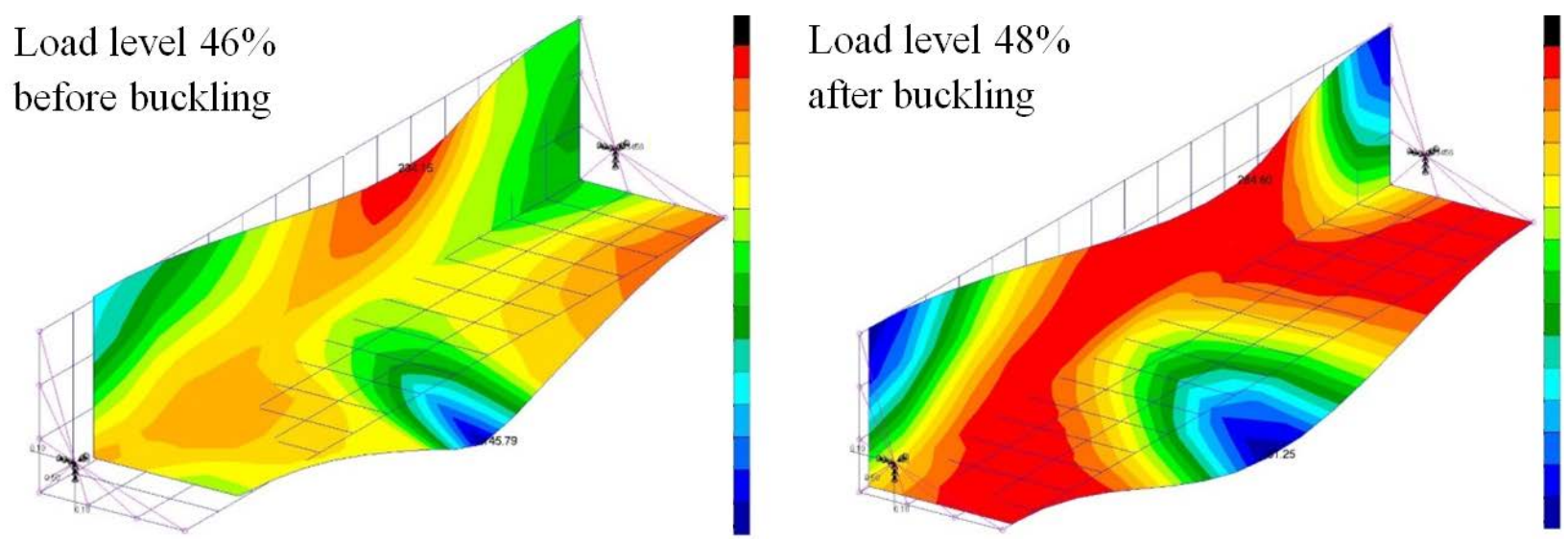

Fig. 4: Graphic visualization of stress distribution on model with imperfection A.

\section{Buckling analyses of FE models with complex types of imperfections}

Following sets of imperfections were designed analogically according to evaluations of the initial set with imperfection A. The second FE model set with imperfection B contained alternating distribution of node imperfections with 5 dimensions along the one flange edge. This model is showed in Figure 5 . The next set with imperfection $\mathrm{C}$ had alternating distributions of node shifts along two free flange edges. Following two sets with imperfections D and E, presented in Figure 5, were designed with alternating node imperfections on entire one flange surface and both flange surfaces. All of these models were computed and evaluated according to designed procedure.
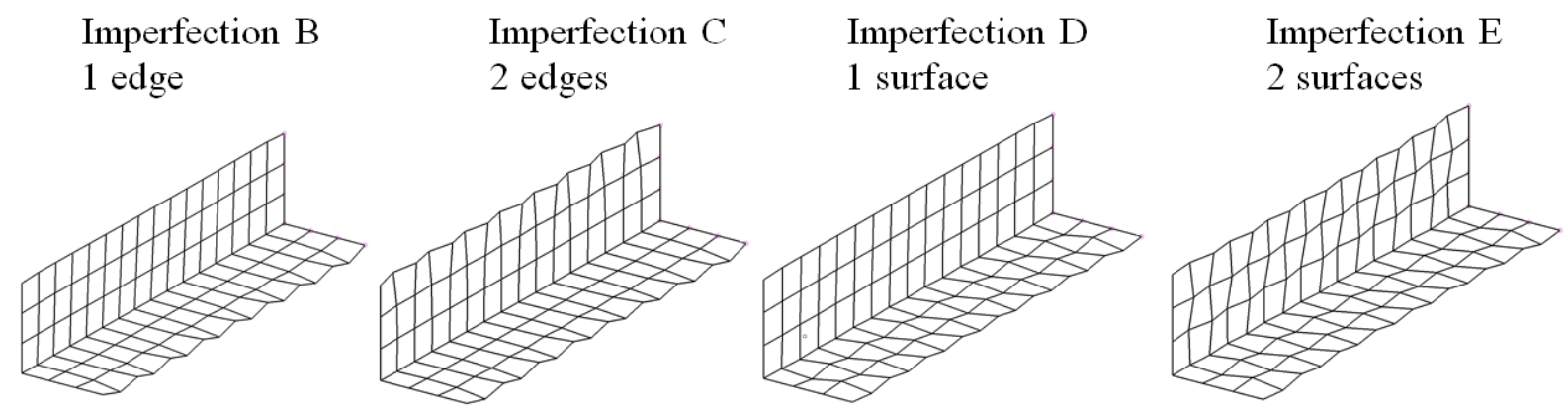

Fig. 5: FE models of particular sets of imperfections. 

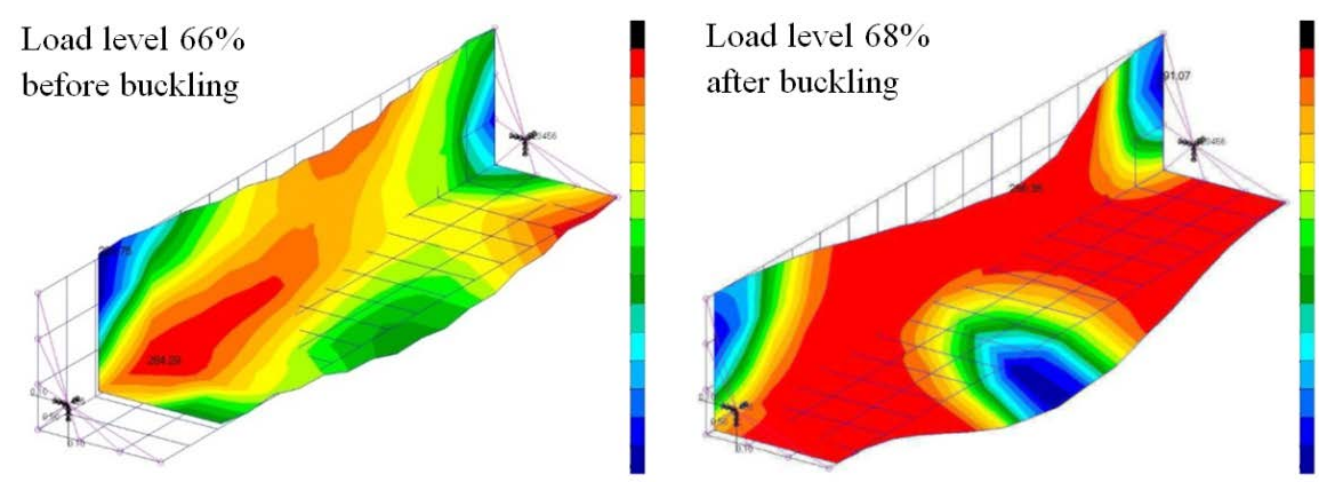

Fig. 6: Graphic visualization of stress distribution on model with imperfection E.

\section{Discussion of results}

Final comparisons in Hála (2017) presented similar trends in effects of imperfection values for all types of sets. An increasing dimension of defect decreased the peak of force distribution and the buckling instability appeared at lower load levels. The ratio e/t value 0.2 for sets of imperfection $\mathrm{A}, \mathrm{B}, \mathrm{C}$ was evaluated as the most suitable dimension of imperfection. The ratio e/t value 0.3 was evaluated as the most suitable dimension for sets of imperfection $\mathrm{D}$ and $\mathrm{E}$. Stress distributions before and after the loss of stability for a set with the imperfection $E$ equal to the best ratio e/t $=0.3$ is presented in Figure 6 . Although a modelling of these imperfections is time consuming, these FE models allow more accurate simulations of critical failures of structural elements in thin-walled semi-monocoque structures. These practical types of irregularities with appropriate ratio values were determined for one constant shape and dimensions of stiffener profile. Following research of influence on buckling is recommended for modifications of outer profile dimensions and mesh density.

\section{Conclusions}

The research of effect on buckling behavior of compressed stiffener with $L$ profile was done with the use of FE methods. Final evaluations of various sets of imperfection types confirmed the necessity of defect application in models where natural curvature of structures is not sufficient. Effects of imperfections on buckling were demonstrated in graphic determination of the critical local loss of stability. Author will use these models and results for following analyses of local buckling of stiffeners with combined compression and bending loads, where references for a safe design are not available.

\section{Acknowledgement}

These outcomes were supported by the project TE02000032 - Advanced Aerostructures Research Centre. This project was realized with financial support from national budget of the Technology Agency of Czech Republic.

\section{References}

Hála, A. (2017) Stability analysis of metal stiffeners under compressive load using finite element methods. VUT v Brně, Brno (in Czech).

Hoff, N. J. (1967) Thin shells in aerospace structures. Journal of Astronautics and Aeronautics, 5, 2, pp. 26-45.

Horák, M. and Píštěk, A. (2016) Shear strength of thin web - influence of lighting openings and diagonal tension. Aviation journal, 20, 1, pp. 8-13.

Jebáček, I. and Matějů, J. (2017) Aerobatic special in-flight tests at Institute of Aerospace Engineering. in: Engineering Mechanics 2017, Brno University of Technology, Brno, pp. 802-805.

Niu, M. C. Y. (1999) Airframe stress analysis and sizing: Practical design information and data on aircraft, second edition. Hong Kong Conmilit Press ltd.

Pravdová, I. and Eliášová, M. (2017) Influence of an initial imperfection on the lateral and torsional buckling of a hybrid beam. in: Engineering Mechanics 2017, Brno University of Technology, Brno, pp. 802-805.

Soares, P. T. M. L., Monteiro, F. A. C., Neto, E. L., Bussamra, F. L. S. (2013) Skin buckling of fuselages under compression. in: Proc. 22nd Int. Congress of Mechanical Engineering COBEM 2013, Brazil, pp. 8976-8985.

Symonov, V., Katrňák, T. (2013) FEM approach to estimate large deformations of stiffened fuselage structure. in: Proc. New Trends in Civil Aviation 2013. 1. Brno, pp. 90-92. 